\title{
Detailed analysis of an idic(Y)(q11.21) in a mosaic karyotype
}

\author{
WALID AL-ACHKAR ${ }^{1}$, ABDULSAMAD WAFA $^{1}$, THOMAS LIEHR $^{2}$, ELISABETH KLEIN $^{2}$ and FATEN MOASSASS ${ }^{1}$ \\ ${ }^{1}$ Department of Molecular Biology and Biotechnology, Division of Human Genetics, Atomic Energy Commission of Syria, \\ Damascus, Syria; ${ }^{2}$ Jena University Hospital, Friedrich Schiller University, Institute of Human Genetics, \\ Kollegiengasse 10, D-07743 Jena, Germany
}

Received November 30, 2011; Accepted February 13, 2012

DOI: $10.3892 / \mathrm{mmr} .2012 .930$

\begin{abstract}
Abnormalities involving sex chromosomes account for approximately $0.5 \%$ of live births. The phenotypes of individuals with mosaic cell lines that exhibit structural aberrations of the $\mathrm{X}$ and $\mathrm{Y}$ chromosomes are variable and difficult to predict. Phenotypes associated with sex chromosome mosaicism vary from females with Turner syndrome to males with infertility, and include individuals with ambiguous genitalia. In this study, we report a 17-year-old male with phenotypic features of Klinefelter syndrome with an isodicentric $\mathrm{Y}$ chromosome and a final karyotype of $45, \mathrm{X}[4] / 46, \mathrm{X}, \operatorname{idic}(\mathrm{Y})$ (q11.21)[95]/47,XX,+idic(Y)(q11.21)[1]. Application of high resolution molecular cytogenetic techniques as well as molecular studies revealed two copies of the sex-determining region of Y chromosome (SRY) gene and two centromers. Additionally, the breakpoint in Yq11.21 was narrowed down between positions 13.4 and 14.3 MB (hg18). We present a patient with partial disomy of Ypter to Yq11.21 in the majority of the patient cells, showing phenotypic features of Klinefelter syndrome. The syndrome may have occurred due to a more prominent presence of the cell line $47, \mathrm{XX},+\operatorname{idic}(\mathrm{Y})(\mathrm{q} 11.21)$ detected only once in $1 \%$ of the peripheral blood cells. This finding may prove helpful in similar cases with symptoms of Klinefelter syndrome, but which exhibit an absence of the cell line $47, \mathrm{XXY}$ in peripheral blood.
\end{abstract}

\section{Introduction}

Structural abnormalities with breakpoints in the euchromatic section of a Y chromosome may lead to its instability and loss in subsequent cell cycles, with formation of a mosaic 45,X cell line. As a result, numerous morphologic forms of the aberrant $\mathrm{Y}$ chromosome occur in the mosaic karyotype.

Correspondence to: Dr Walid Al-Achkar, Department of Molecular Biology and Biotechnology, Division of Human Genetics, Atomic Energy Commission of Syria, P.O. Box 6091, Damascus, Syria

E-mail: ascientific@aec.org.sy

Key words: isodicentric Y chromosome, ambiguous genitalia, fluorescence in situ hybridization, multicolor banding, sequencing, sex-determining region $\mathrm{Y}$, azoospermia factor
Dicentrics are the most common structural abnormalities of the $\mathrm{Y}$ chromosome $(1,2)$. They are mitotically unstable and may consequently be lost during development, resulting in the majority of patients with dicentric Y chromosome having a mosaic karyotype, mostly with a 45,X cell line (3). Clinical features of such patients may range from Turner-syndromelike females to infertile males, depending on the structure of the dicentric Y chromosome, the sites of breakage and types of mosaicism.

The identification of $\mathrm{Y}$ chromosome-derived material in cases with dysgenetic gonads is associated with an increased risk of developing gonadoblastoma. The presence of a Y chromosome, or part of it, is associated with a $25-70 \%$ risk of gonadoblastoma, the highest risk being associated with mixed gonadal dysgenesis and increasing age (4). In patients with the $45, \mathrm{X} / 46, \mathrm{XY}$ karyotype, the risk appears lowest in phenotypic males, intermediate $(0.5 \%)$ in patients with ambiguous external genitalia and highest (22\%) in phenotypic females (1).

The Y chromosome contains crucial loci for normal male sexual development. The sex-determining region of the Y chromosome (SRY), a transcription factor on the short arm of the $\mathrm{Y}$ chromosome, is the critical switch leading to testis development. Mutations in SRY result in XY individuals developing as females; patients with a 45,X karyotype with insertion of SRY into an autosome have a male phenotype $(5,6)$. Genes in the euchromatic region of the long arm of the Y chromosome (Yq11) are required for normal spermatogenesis, and Y chromosome microdeletions are an important genetic cause of primary testiculopathies. Deletion mapping was directed at the identification of genes related to spermatogenesis, and defined three regions as the azoospermia factors (AZFa, AZFb and $\mathrm{AZFc}$ ) mapped to $\mathrm{Yq} 11$ (7). The main candidate gene in AZFc is the DAZ (deleted in azoospermia) cluster, a set of genes transcribed in the testis and expressed exclusively in germ cells, apparently encoding an RNA binding protein (8).

In this study, we present a detailed molecular-cytogenetic characterization of a patient with phenotypic features of the Klinefelter syndrome with mosaicism involving an isodicentric Y chromosome.

\section{Patient and methods}

Patient history. A 17-year-old male was referred for cytogenetic analysis in October 2008 due to a small penis with small testes (the right and left testicular volume of 4 and 


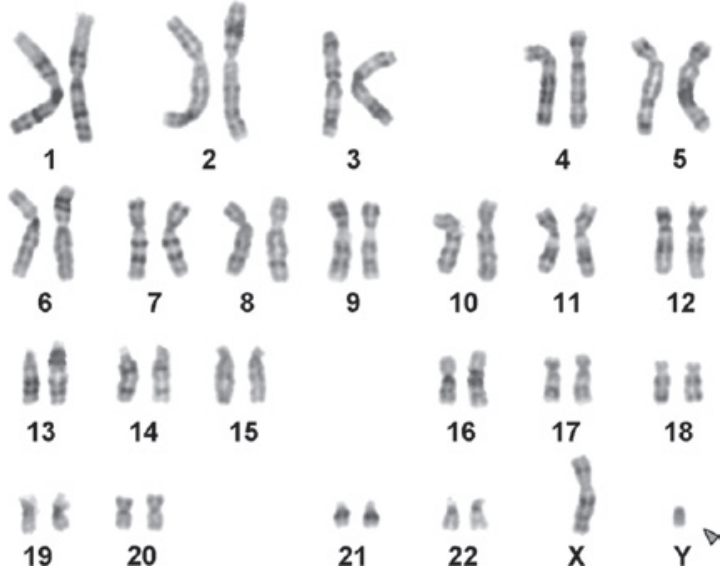

Figure 1. Karyotype from a peripheral blood metaphase of the patient showing 46,X,idic(Y)(q11.21).

$4.5 \mathrm{ml}$, respectively). Informed consent was obtained from the patient and ethics approval for the study was provided by the Bio-safety and Bioethics Member Committee/S.A.E.C. The patient's weight was $69 \mathrm{~kg}$, with a height of $170 \mathrm{~cm}$, and he did not show any dysmorphic signs or symptoms. The mother was a 37-year-old healthy female without any signs or symptoms of virilization or drug abuse during pregnancy. The mother's and the father's height were 167 and $184 \mathrm{~cm}$, respectively. No family history of sterility or abortion was reported. Ultrasound of the pelvis area revealed no uterus and ovaries. Laboratory examination showed FSH levels of $2.1 \mathrm{mIU} / \mathrm{ml}$, LH levels of $1.6 \mathrm{mIU} / \mathrm{ml}$ and a testosterone concentration of $0.89 \mathrm{ng} / \mathrm{dl}$. Volume semen analysis was $2.5 \mathrm{ml}$.

Cytogenetic and molecular cytogenetics analysis. Cytogenetic analysis using GTG-banding was performed according to standard procedures (9). A total of 100 metaphases analyzed from stimulated peripheral blood cultures were analyzed. Karyotypes were described according to the International System for Human Cytogenetic Nomenclature (10).

Fluorescence in situ hybridization (FISH) was carried out on the metaphases using a commercially available probes whole painting chromosome (WCP), LSI SRY, subtelomeric for Xp/ Yp and Xq/Yq, centromeric for X and Y (DXZ1; DYZ3) (Abbott Molecular/Vysis, Des Plaines, IL, USA) and Y chromosomespecific multicolor banding (MCB). The procedure was performed as described in a previous study (11). A total of 50-100 metaphase spreads were analyzed. The results were evaluated on a fluorescence microscope (AxioImager.Z1 mot, Zeiss) equipped with appropriate filter sets to discriminate between a maximum of five fluorochromes and the counterstain DAPI (4',6'-diamino-2-phenylindole). Image capturing and processing were carried out using an Isis imaging system (MetaSystems, Altlussheim, Germany) for the evaluation of MCB.

Molecular analysis. Genomic DNA was extracted from peripheral blood using Genequality AZF MX kit (AB Analitica, Italy) according to the manufacturer's instructions. To screen for Y-specific regions, we tested for the presence of 26 Y-DNA loci via a sequence-tagged site (STS) and genes. The STS primers tested were: sY81, sY82, sY84, sY86, DBY, USP9Y (AZFa); sY95; sY117, sY121, sY124, sY125, sY127, sY134,
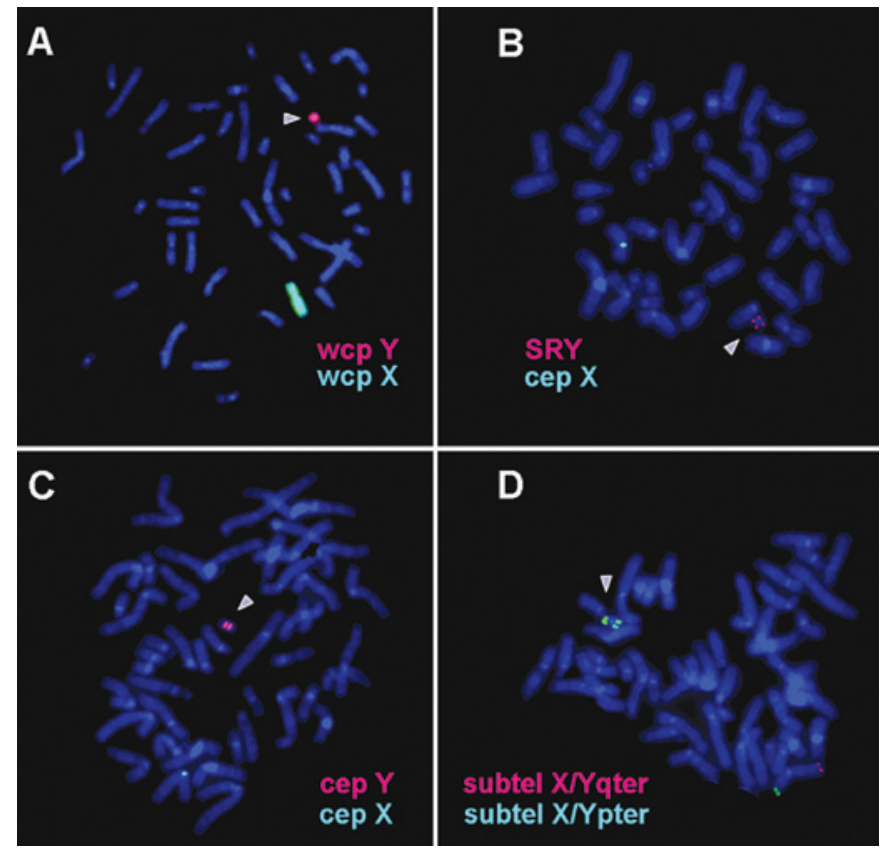

Figure 2. (A) Fluorescence in situ hybridization (FISH) using probes for whole painting chromosome $\mathrm{X}$ (green) and $\mathrm{Y}$ (red) showing one red signal is on the $\operatorname{der}(\mathrm{Y})$ and one green signal is on the chromosome X. (B) FISH using probes for the sex-determining region of $\mathrm{Y}$ chromosome (SRY) (red) and CEP X (green) showing two red signals is on the der(Y), one green signal is on the chromosome X. (C) FISH using probes for CEP Y (red) and CEP X (green) showing two red signals is on the $\operatorname{der}(\mathrm{Y})$, one green signal is on the chromosome X. (D) FISH using probes for ST Xp/Yp (green) and ST Xq/ Yq (red) showing two green signals is on the $\operatorname{der}(\mathrm{Y})$, one green and one red signals is on the chromosome $\mathrm{X}$.
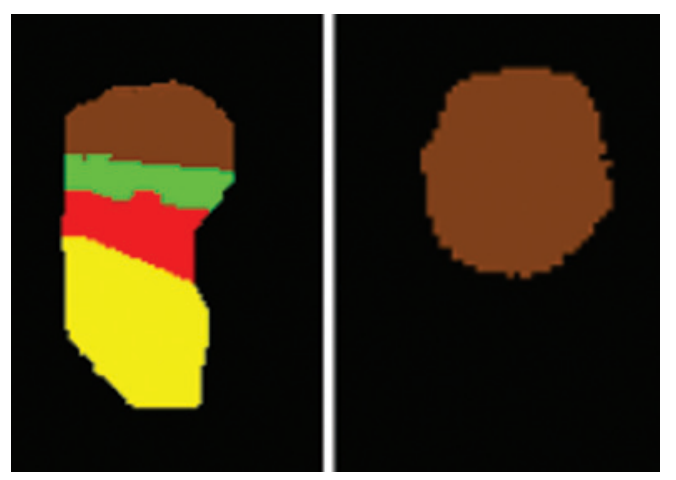

Figure 3. Multicolor banding (MCB) with Y chromosome probe showing idic $\mathrm{Y}(\mathrm{q} 11.21$ ) (right panel) in comparison to a normal $\mathrm{Y}$ chromosome (left panel).

sY142, sY143 (AZFb); sY147, sY149, sY158, sY239, sY242, sY254 (DAZ), sY255 (DAZ), sY283 (AZFc); sY145, sY153 (AZFd). Moreover, sY160 (heterochromatin region) and human zinc-finger protein-encoding genes (ZFX/ZFY) located on the $X$ and $Y$ chromosomes were selected. The ZFX/ZFY and SRY (i.e., STS sY14) acted as internal control primers. Following an initial denaturation step at $94^{\circ} \mathrm{C}$ for $5 \mathrm{~min}$, cycle parameters were: 40 cycles at $94^{\circ} \mathrm{C}$ for $1 \mathrm{~min}, 60^{\circ} \mathrm{C}$ for $1 \mathrm{~min}$, and $72^{\circ} \mathrm{C}$ for $1 \mathrm{~min}$. The program was followed by the final extension step at $72^{\circ} \mathrm{C}$ for $5 \mathrm{~min}$. The reaction products were electrophoresed on an ethidium bromide-stained $2.5 \%$ agarose-TAE-gel and observed under UV-light. 


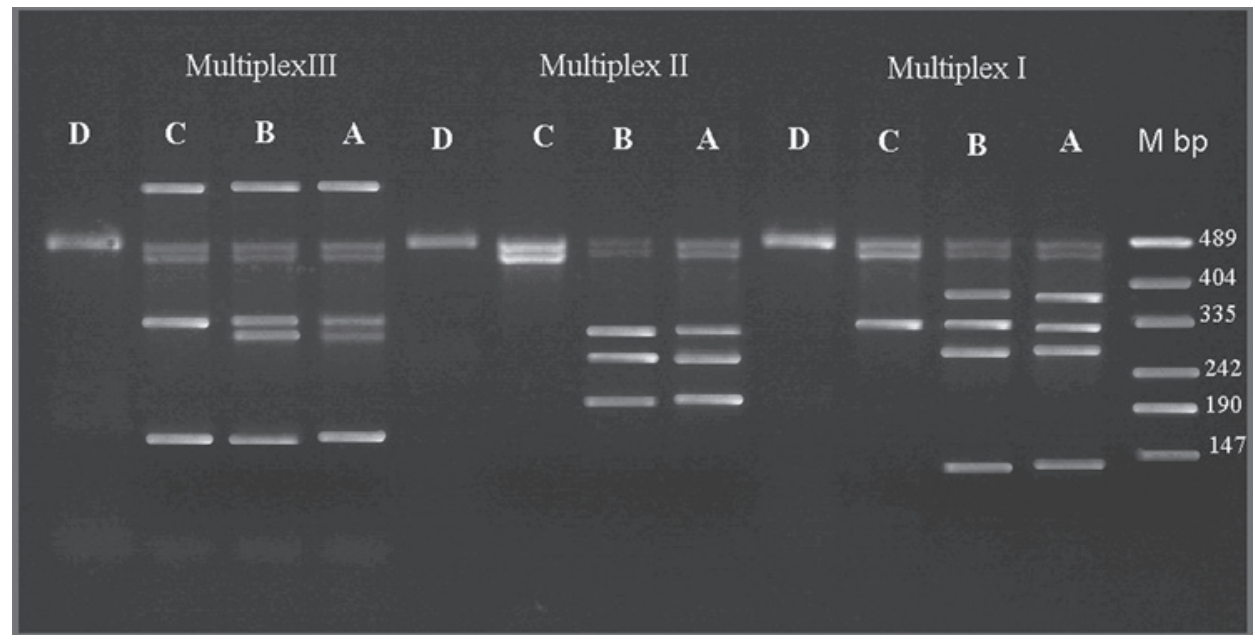

Figure 4. Multiplex PCR for the presence or absence of 26 Y-specific loci were analyzed in the patient with a Y chromosome deletion. Multiplex I: Zinc-finger protein-encoding genes (ZFX/ZFY) (495 bp), sex-determining region of Y chromosome (SRY) (472 bp), sY254 (380 bp), sY86 (320 bp), sY127 (274 bp) and sY255 (120 bp); Multiplex II: ZFX/ZFY (495 bp), SRY (472 bp), sY95 (303 bp), sY117 (262 bp) and sY125 (200 bp); and Multiplex III: DBY (689 bp), ZFX/ ZFY (495 bp), SRY (47 bp), sY84 (326 bp), sY134 (301 bp) and DFFRY (155 bp). This patient had seven (sY95, sY117, sY125, sY127, sY134, sY254 and sY255) deletions. Each reaction was compared with a fertile man serving as the control (A and B); C, DNA sample of patient; D, sample from a woman as a negative control; and M, DNA molecular weight marker. Additionally the loci (sY145, sY147, sY149, sY158 and sY283) were deleted (data not shown).

PCR amplification of SRY and sequencing analysis. According to the procedure of Al-Achkar et al (12), mutation screening was carried out using direct DNA sequence analysis. The whole coding sequence of the SRY gene was amplified by PCR using the primers previously described (13).

\section{Results}

The karyotype determined by GTG-banding was identified as mos 45,X/46,X,+mar/47,XX,+mar (Fig. 1). FISH using a $\mathrm{Y}$ chromosome-specific whole chromosome painting probe stained the entire derivative chromosome (Fig. 2A). Findings of dual color FISH experiments (Fig. 2B-D) showed that the chromosome was an isodicentric mainly derived from the short arm of the Y chromosome. Together with the MCB-findings (Fig. 3) the karyotype was obtained was: 45,X[4]/46,X,idic(Y) (q11.21)[95]/47,XX,+idic(Y)(q11.21)[1].

The presence or absence of $26 \mathrm{Y}$-specific loci was analyzed molecularly. Of the 26 loci, 12 loci were absent in the present case: sY95, sY117, sY125, sY127, sY134, sY145, sY147, sY149, sY158, sY254, sY255 and sY283 (Fig. 4). Thus, the breakpoint of the derivative $\mathrm{Y}$ chromosome was determined to be between marker sY84 (13.4 MB) and sY95 (15.1 MB). According to cytogenetics, the breakpoint was in band Yq11.21, located between 12.5 and 14.3 MB. Therefore, the breakpoint is likely to be between 13.4 and 14.3 MB (hg18).

To identify a possible mutation, we analyzed the SRYspecific PCR fragment by DNA sequencing using a normal male as a control. No mutation was exhibited by the patient (data not shown).

\section{Discussion}

The most common abnormality in the human Y chromosome is a dicentric derivative present as part of a mosaic karyotype including a 45,X cell line (3). A number of mechanisms of dicentric isochromosome formation have been described and the most frequent mechanism of this alteration is the sister-chromatid breakage and reunion (14-17). Isodicentric $\mathrm{Y}$ chromosomes appear to be formed by a single break in one of the Y chromatids, followed by a fusion of the broken ends of sister chromatids and the loss of the acentric fragment during gametogenesis prior to the formation of spermatids. Such rearrangements are generally unstable and an additional $45, X$ cell line is frequently present (18). Patients with dicentric isochromosome $\mathrm{Y}$ are mosaics without a 46,XY cell line, indicating that gametogenic or early post-zygotic origins are the most frequent (1), and a $45, \mathrm{X}$ cell line is usually found as part of this mosaicism at the same time $(1,3)$. In the present study, the dicentric isochromosome $\mathrm{Y}$ was also mosaic but without a normal cell line $(1,3)$.

Although in the literature patients with mosaic karyotypes 45,X/46,X,idic(Y)(q11.21) have frequently been described (http://www.med.uni-jena.de/fish/sSMC/sturner.html), the present patient is to the best of our knowledge the first case with mos 45,X/46,X,idic(Y)(q11.21)/47,XX,+idic(Y)(q11.21) and a Klinefelter syndrome phenotype.

The Klinefelter syndrome is most common, occurring in 1:500 to 1:1000 live births (19). The phenotype of patients is variable such as tall stature, hypogonadism, gynecomastia, small testes, decreased facial hair, small penis, infertility and low testosterone (20). The classic form of Klinefelter syndrome is the polyploidy (extra chromosome) condition of 47,XXY, which characterizes $80 \%$ of Klinefelter cases. Another $15 \%$ of the cases are mosaic types (46,XY/47,XXY, 46,XY/48,XXYY, $45, X 0 / 46, X Y / 47, X X Y$ and $46 X X / 47, X X Y)$. The remaining $5 \%$ are $\mathrm{XX}$ forms with the SRY gene (testes determining factor) translocated to an $\mathrm{X}$ chromosome, Poly $\mathrm{X}+\mathrm{Y}$ forms, or combined mosaic and poly $\mathrm{X}+\mathrm{Y}$ forms (21). In the present study, the $47, \mathrm{XX},+\mathrm{idic}(\mathrm{Y})(\mathrm{q} 11.21)$ condition was present in only $1 \%$ of the peripheral blood cells.

The presence of a $\mathrm{Y}$ chromosome is associated with a $25-70 \%$ risk, the highest risk being associated with mixed gonadal dysgenesis and increasing age. The development of 
gonadoblastoma is thought to be less common in patients with $\operatorname{idic}(\mathrm{Y})(\mathrm{q} 11.2)(22)$.

In conclusion, we present a rare case of a clinical presentation of Klinefelter syndrome with only $1 \%$ of the peripheral blood cells having the causative two X-chromosomes. We suggest that the patient has more cells with $47, \mathrm{XX},+\operatorname{idic}(\mathrm{Y})$ (q11.21) karyotype in other tissues. This case may be useful to explain similar clinical Klinefelter syndrome cases without typical karyotypic findings in peripheral blood. The breakpoint of the derivative $\mathrm{Y}$ chromosome was also narrowed down to $0.9 \mathrm{MB}$.

\section{Acknowledgements}

The authors thank Professor I. Othman, General Director of Atomic Energy Commission of SYRIA (AECS) and Dr N. Mirali, Head of the Department of Molecular Biology and Biotechnology for their support. This study was supported by the Syrian Atomic Energy Commission and the Else Kröner-Fresenius-Stiftung.

\section{References}

1. Hsu LY: Phenotype/karyotype correlations of Y chromosome aneuploidy with emphasis on structural aberrations in postnatally diagnosed cases. Am J Med Genet 53: 108-140, 1994.

2. Yoshida A, Nakahori Y, Kuroki Y, Motoyama M, Araki Y, Miura K and Shirai MM: Dicentric Y chromosome in an azoospermic male. Mol Hum Reprod 3: 709-712, 1997.

3. Tuck-Muller CM, Chen H, Martinez JE, Shen CC, Li S, Kusyk C, Batista DA, Bhatnagar YM, Dowling E and Wertelecki W: Isodicentric Y chromosome: cytogenetic, molecular and clinica studies and review of the literature. Hum Genet 96: 119-129, 1995

4. Krasna IH, Lee ML, Smilow P, Sciorra L and Eierman L: Risk of malignancy in bilateral streak gonads: the role of the $\mathrm{Y}$ chromosome. J Pediatr Surg 27: 1376-1380, 1992.

5. Sinclair AH, Berta P, Palmer MS, Hawkins JR, Griffiths BL, Smith MJ, Foster JW, Frischauf AM, Lovell-Badge R and Goodfellow PN: A gene from the human sex-determining region encodes a protein with homology to a conserved DNA-binding motif. Nature 346: 240-244, 1990.

6. Yenamandra A, Deangelo P, Aviv H, Suslak L and Desposito F: Interstitial insertion of Y-specific DNA sequences including SRY into chromosome 4 in a 45,X male child. Am J Med Genet 72: 125-128, 1997.

7. Yen PH: A long-range restriction map of deletion interval 6 of the human Y chromosome: a region frequently deleted in azoospermic males. Genomics 54: 5-12, 1998.
8. Reijo R, Lee TY, Salo P, Alagappan R, Brown LG, Rosenberg M, Rozen S, Jaffe T, Straus D, Hovatta O, et al: Diverse spermatogenic defects in humans caused by $\mathrm{Y}$ chromosome deletions encompassing a novel RNA-binding protein gene. Nat Genet 10: 383-393, 1995.

9. Al-Achkar W, Wafa A, Moassass F and Liehr T: Partial trisomy 9p22 to 9p24.2 in combination with partial monosomy 9pter in a Syrian girl: a case report. Mol Cytogenet 3: 18, 2010.

10. Shaffer L, Slovak M and Cambell L (eds): ISCN (2009): An International System for Human Cytogenetic Nomenclature. S. Karger, Basel, 2009.

11. Liehr T, Heller A, Starke H, Rubtsov N, Trifonov V, Mrasek K, Weise A, Kuechler A and Claussen U: Microdissection based high resolution multicolor banding for all 24 human chromosomes. Int J Mol Med 9: 335-339, 2002.

12. Al-AchkarW, Moassass F,Al-Halabi B and Al-Ablog A: Mutations of the Connexin 26 gene in families with non-syndromic hearing loss. Mol Med Report 4: 331-335, 2011.

13. Wang X, Wang XR, Liu MG, Wang Q and Liu JY: Genetic analysis of a family with $46, X Y$ 'female' associated with infertility. Acta Genetica Sinica 33: 19-25, 2006.

14. Therman E, Sarto GE and Patau K: Apparently isodicentric but functionally monocentric X chromosome in man. Am J Hum Genet 26: 83-92, 1974

15. Wolff DJ, Miller AP, Van Dyke DL, Schwartz S and Willard HF: Molecular definition of breakpoints associated with human $\mathrm{Xq}$ isochromosomes: implications for mechanisms of formation. Am J Hum Genet 58: 154-160, 1996.

16. Robinson DO, Dalton P, Jacobs PA, Mosse K, Power MM, Skuse DH and Crolla JA: A molecular and FISH analysis of structurally abnormal Y chromosomes in patients with Turner syndrome. J Med Genet 36: 279-284, 1999.

17. Codina-Pascual M, Oliver-Bonet M, Navarro J, Starke H, Liehr T, Gutiérrez-Mateo C, Sánchez-García JF, Arango O, Egozcue J and Benet J: FISH characterization of a dicentric Yq (p11.32) isochromosome in an azoospermic male. Am J Med Genet A 127A: 302-306, 2004.

18. Quilter CR, Nathwani N, Conway GS, Stanhope R, Ralph D, Bahadur G, Serhal P, Taylor K and Delhanty JD: A comparative study between infertile males and patients with Turner syndrome to determine the influence of sex chromosome mosaicism and the breakpoints of structurally abnormal Y chromosomes on phenotypic sex. J Med Genet 39: e80, 2002.

19. Hamberton JL, Canning N, Ray M and Smith S: A cytogenetic survey of 14,069 newborn infants. I. Incidence of chromosome abnormalities. Clin Genet 8: 223-243, 1975.

20. Smyth CM and Bremner WJ: Klinefelter syndrome. Arch Intern Med 158: 1309-1314, 1998.

21. Paulsen CA, Gordon DL, Carpenter RW, Gandy HM and Drucker WD: Klinefelter's syndrome and its variants: a hormonal and chromosomal study. Recent Prog Horm Res 24: 321-363, 1968.

22. Lukusa T, Fryns JP and van den Berghe H: Gonadoblastoma and Y-chromosome fluorescence. Clin Genet 29: 311-316, 1986. 